\title{
trabalhonecessário
}

ano 2 - número 2 - 2004

\section{ELEMENTOS PARA CONSTRUÇÃO DO PROJETO POLÍTICO E PEDAGÓGICO DA EDUCAÇÃO DO CAMPO [1]}

Roseli Salete Caldart [2]

\section{Momento Atual da Educação do Campo}

Passaram-se quase 6 anos da I Conferência Nacional Por Uma Educação Básica do Campo, realizada em 1998, e que foi o momento de batismo coletivo de um novo jeito de lutar e de pensar a educação para o povo brasileiro que trabalha e vive no e do campo. Através do processo de construção desta Conferência os Movimentos Sociais do Campo inauguraram uma nova referência para o debate e a mobilização popular: Educação do Campo e não mais educação rural ou educação para o meio rural.[3]

$\mathrm{Na}$ I Conferência reafirmamos que o campo é espaço de vida digna e que é legítima a luta por políticas públicas específicas e por um projeto educativo próprio para seus sujeitos. Também foram denunciados os graves problemas de falta de acesso e de baixa qualidade da educação pública destinada à população trabalhadora do campo. Discutimos propostas, socializamos experiências de resistência no campo e de afirmação de um outro projeto de educação. De lá para cá o trabalho continuou através da articulação nacional Por Uma Educação do Campo, que seguiu nas mobilizações nos estados e no debate com a sociedade, levando esta mensagem especialmente para outros movimentos sociais e para as educadoras e os educadores do campo.

Uma conquista recente do conjunto das organizações de trabalhadores e trabalhadoras do campo, no âmbito da luta por políticas públicas, foi a aprovação das "Diretrizes Operacionais para a Educação Básica nas Escolas do Campo" (Parecer n 36/2001 e Resolução 1/2002 do Conselho Nacional de Educação). Outra conquista política importante está sendo a entrada da questão da Educação do Campo na agenda de lutas e de trabalho de um número cada vez maior de movimentos sociais e sindicais de trabalhadores e trabalhadoras do campo, o que vem pressionando sua inclusão na agenda de alguns governos municipais, estaduais e também na agenda do governo federal.[4]

A articulação e o movimento foram denominados inicialmente de por uma educação básica do campo; a partir dos debates realizados no seminário nacional de 2002 alteramos o nome para por uma Educação do 
Campo, em vista de afirmar, primeiro, que não queremos educação só na escola formal: temos direito ao conjunto de processos formativos já constituídos pela humanidade; e, segundo, que o direito à escola pública do campo pela qual lutamos compreende da educação infantil à Universidade.[5]

O momento atual nos parece propício para avanços, ao mesmo tempo em que revela uma maior complexidade para a atuação dos Movimentos Sociais: o campo está voltando à agenda do debate político do país, sendo parte da disputa de projetos de desenvolvimento, mas em um contexto de clara hegemonia do projeto do capital, que até poderá reeditar uma política de "educação para o meio rural", mas não tem como admitir que o Estado assuma a construção efetiva de um sistema público de Educação do Campo.

O desafio que se impõe hoje aos sujeitos da Educação do Campo é o da práxis: avançar na clareza teórica e de projeto para poder dar um salto de qualidade na luta política e nas práticas pedagógicas produzidas até aqui. É preciso significar o nome que criamos, e constituir teórica e politicamente o conteúdo e a forma desta nova bandeira. Este desafio nos exige um permanente retorno a uma questão de origem: o que é mesmo a Educação do Campo e quais são os seus fundamentos principais?

O desafio teórico atual é o de construir o paradigma (contra-hegemônico) da Educação do Campo: produzir teorias, construir, consolidar e disseminar nossas concepções, ou seja, os conceitos, o modo de ver, as idéias que conformam uma interpretação e uma tomada de posição diante da realidade que se constitui pela relação entre campo e educação. Trata-se, ao mesmo tempo de socializar/quantificar a compreensão do acúmulo teórico e prático que já temos, e de continuar a elaboração e o planejamento dos próximos passos.

Este desafio se desdobra em três tarefas combinadas: manter viva a memória da Educação do Campo, continuando e dinamizando sua construção e reconstrução pelos seus próprios sujeitos; identificar as dimensões fundamentais da luta política a ser feita no momento atual; e seguir na construção do projeto político e pedagógico da Educação do Campo.

O texto que segue busca refletir especialmente na direção desta terceira tarefa, combinada com a primeira, trazendo para o debate alguns elementos a serem considerados na construção deste projeto.

Não se trata de 'inventar' um ideário para a Educação do Campo; isso não repercutiria na realidade concreta, que é a que nos interessa transformar, e nem seria uma verdadeira teoria. O desafio que temos, enquanto sujeitos que colocaram esta 'bandeira em marcha', é de abstrair das experiências, dos debates, das disputas em curso, um conjunto de idéias que possam orientar o pensar (especialmente dos educadores) sobre a prática de educação da classe trabalhadora do campo; e, sobretudo, possam orientar e projetar outras práticas e políticas de educação. Por isso esse é um trabalho que será tanto mais legítimo quanto realizado de modo coletivo. As idéias aqui expostas fazem parte deste movimento.

\section{Traços de identidade da Educação do Campo}

Nossa proposta é pensar a Educação do Campo como processo de construção de um projeto de educação dos trabalhadores e das trabalhadoras do campo, gestado desde o ponto de vista dos camponeses [6] e da trajetória de luta de suas organizações. Isto quer dizer que se trata de pensar a educação (política e pedagogia) desde os interesses sociais, políticos, culturais de um determinado grupo social; ou trata-se de pensar a educação (que é um processo universal) desde uma particularidade, ou seja, desde sujeitos 
concretos que se movimentam dentro de determinadas condições sociais de existência em um dado tempo histórico. A Educação do Campo assume sua particularidade, que é o vínculo com sujeitos sociais concretos, e com um recorte específico de classe, mas sem deixar de considerar a dimensão da universalidade: antes (durante e depois) de tudo ela é educação, formação de seres humanos. Ou seja, a Educação do Campo faz o diálogo com a teoria pedagógica desde a realidade particular dos camponeses, mas preocupada com a educação do conjunto da população trabalhadora do campo e, mais amplamente, com a formação humana. E, sobretudo, trata de construir uma educação do povo do campo e não apenas com ele, nem muito menos para ele.

Um dos fundamentos da construção deste projeto é a compreensão da sua materialidade de origem. E este, aliás, pode ser um bom ponto de partida para clarear as concepções desde o ponto de vista de quem tem compromisso com sua raiz, sua memória.

Em resumo, podemos dizer que no contexto originário da Educação do Campo há como elementos principais: - o campo e a situação social objetiva das famílias trabalhadoras nessa época: o aumento da pobreza, a degradação da qualidade de vida, o aumento da desigualdade social, da exclusão; a barbárie provocada pela implantação violenta do modelo capitalista de agricultura; - neste mesmo contexto a situação em relação à educação: ausência de políticas públicas que garantam o direito à educação e à escola para os camponeses/trabalhadores do campo; - ao mesmo tempo a emergência de lutas e de sujeitos coletivos reagindo a esta situação social; especialmente as lutas camponesas, e entre elas, a luta pela terra e pela Reforma Agrária; - também o debate de uma outra concepção de campo e de projeto de desenvolvimento que sustente uma nova qualidade de vida para a população que vive e trabalha no campo; - vinculadas ou não a estas lutas sociais, a presença significativa de experiências educativas que expressam a resistência cultural e política do povo camponês frente às diferentes tentativas de sua destruição.

A Educação do Campo se constitui a partir de uma contradição que é a própria contradição de classe no campo: existe uma incompatibilidade de origem entre a agricultura capitalista e a Educação do Campo, exatamente porque a primeira sobrevive da exclusão e morte dos camponeses, que são os sujeitos principais da segunda. Em nosso debate isto tem sido referido como a principal oposição com a educação rural ou para o meio rural, que historicamente tem sido o nome dado às iniciativas do Estado de pensar a educação da população trabalhadora do campo, de modo a escamotear esta contradição e fazê-la de objeto e instrumento executor de políticas e de modelos de agricultura pensados em outros lugares, e para atender a outros interesses que não os seus enquanto grupo social, enquanto classe, enquanto pessoas.[7]

O movimento inicial da Educação do Campo foi o de uma articulação política de organizações e entidades para denúncia e luta por políticas públicas de educação no e do campo, e para mobilização popular em torno de um outro projeto de desenvolvimento. Ao mesmo tempo tem sido um movimento de reflexão pedagógica das experiências de resistência camponesa, constituindo a expressão, e aos poucos o conceito de Educação do Campo.

Outro fundamento da construção deste projeto político e pedagógico é o diálogo com a teoria pedagógica. Não foi a pedagogia que inventou a Educação do Campo, mas ela não se constitui como um projeto de educação sem o diálogo com a teoria pedagógica, com as questões universais da pedagogia e da educação.

file://C:|Documents and Settings\AdministradorlMeus documentos\Minhas Webs\NED... 28/8/2008 
O diálogo se dá em torno de uma concepção de ser humano, cuja formação é necessária para a própria implementação do projeto de campo e de sociedade que integra o projeto da Educação do Campo.

E o diálogo principal terá que ser com uma determinada tradição pedagógica crítica, vinculada a objetivos políticos de emancipação e de luta por justiça e igualdade social. Neste veio teórico há pelo menos três referências prioritárias. A primeira delas é a tradição do pensamento pedagógico socialista, que pode nos ajudar a pensar a relação entre educação e produção desde a realidade particular dos sujeitos do campo; também nos traz a dimensão pedagógica do trabalho e da organização coletiva, e a reflexão sobre a dimensão da cultura no processo histórico, e que podemos hoje combinar com algumas questões específicas dos processos de aprendizagem e ensino que nos vêm de estudos mais recentes da psicologia sociocultural e de outras ciências que buscam compreender mais a fundo a arte de educar, desde uma perspectiva humanista e crítica.

A segunda referência para esta interlocução é a Pedagogia do Oprimido e toda a tradição pedagógica decorrente das experiências da Educação Popular, que incluem o diálogo com as matrizes pedagógicas da opressão (a dimensão educativa da própria condição de oprimido) e da cultura (a cultura como formadora do ser humano), especialmente em Paulo Freire. A Educação do Campo talvez possa ser considerada uma das realizações práticas da pedagogia do oprimido, à medida que afirma os pobres do campo como sujeitos legítimos de um projeto emancipatório, e por isso mesmo, educativo.

E a terceira referência pedagógica para a Educação do Campo vem de uma reflexão teórica mais recente, que estamos chamando de Pedagogia do Movimento, e que também dialoga com as tradições anteriores, mas se produz desde as experiências educativas dos próprios Movimentos Sociais, e em especial dos Movimentos Sociais do Campo. Trata-se de uma matriz pedagógica cuja constituição teórica se dá no mesmo tempo histórico da Educação do Campo. Podemos dizer então que se trata de um diálogo que ao mesmo tempo será formulação de suas concepções e de seus desdobramentos práticos. Esta é, pois, uma reflexão pedagógica que a Educação do Campo está ajudando a construir, na perspectiva talvez de chegarmos a produzir uma tradição pedagógica que tenha como referências o campo e as lutas sociais.

Pressupondo, então, este início de diálogo que já existe entre uma leitura da materialidade de origem da Educação do Campo e este veio da teoria pedagógica, podemos prosseguir na reflexão proposta por este texto e identificar alguns traços considerados fundamentais na construção do projeto político e pedagógico da Educação do Campo. São os seguintes:

\section{Formação humana vinculada a uma concepção de campo.}

A materialidade de origem da Educação do Campo projeta/constrói uma determinada totalidade de relações que Ihes são constitutivas. Antes (ou junto) de uma concepção de educação ela é uma concepção de campo: porque, neste caso, como pensamos o campo pensamos a educação; se pensarmos o campo como latifúndio não temos como pensar a Educação do Campo; se pensarmos a Reforma Agrária como uma política social ou compensatória apenas, não vamos pensar em um sistema público de educação para os camponeses.

Esta é uma idéia muito importante na própria concepção de educação: de certo modo ela recupera um dos 
elementos constituintes da história da pedagogia e reforça uma idéia forte nos Movimentos Sociais: o vínculo de origem da educação, ou de um projeto educativo, com um projeto político, com um projeto social. A teoria pedagógica historicamente surgiu para dar conta da intencionalidade da formação do ser humano capaz de ser sujeito construtor de um determinado projeto de sociedade. E muitas vezes esta vocação de origem é escamoteada, ou afirmada como 'coisa da esquerda'.

Pensar a educação desde ou junto com uma concepção de campo significa assumir uma visão de totalidade dos processos sociais; no campo dos Movimentos Sociais significa um alargamento das questões da agenda de lutas; no campo da política pública significa pensar a relação entre uma política agrária e uma política de educação, por exemplo; ou entre política agrícola, política de saúde, e política de educação. E na dimensão da reflexão pedagógica significa discutir a arte de educar, e os processos de formação humana, a partir dos parâmetros de um ser humano concreto e historicamente situado.

A visão de campo da Educação do Campo está em construção. É um dos desafios do debate político e teórico em curso. Mas há algumas questões/posições que já foram incorporadas ao nosso ideário:

a) A Educação do Campo é incompatível com o modelo de agricultura capitalista que combina hoje no Brasil latifúndio e agronegócio, exatamente porque eles representam a exclusão da maioria e a morte dos camponeses.[8] Educação do Campo combina com Reforma Agrária, com Agricultura Camponesa, com agroecologia popular. E é este, pois, o debate político que nos interessa fazer: como combater o latifúndio e a agricultura centrada no negócio; e como fortalecer um modelo popular de agricultura, identificando as características da produção camponesa que devem ser preservadas, e também as que devem ser transformadas na perspectiva de um outro projeto de desenvolvimento.

b) A Educação do Campo tem um vínculo de origem com as lutas sociais camponesas. Pensa a educação dos sujeitos do campo desde o vínculo com a luta pelos direitos das mulheres camponesas, com a luta pela reforma agrária e por um projeto camponês de desenvolvimento do campo, com a luta pela democratização do acesso à água; com a luta das crianças pelo seu direito à infância... A Educação do Campo não precisa e nem deve ser um projeto de educação apenas dos camponeses, nem apenas de quem participa de lutas sociais; mas este vínculo lhe confere um traço de identidade importante e que não pode ser perdido.

c) A Educação do Campo defende a superação da antinomia rural e urbano e da visão predominante de que o moderno e mais avançado é sempre o urbano, e que a tendência de progresso de uma localidade se mede pela diminuição de sua população rural. Existe toda uma outra matriz de pensamento, com a qual nos identificamos, que busca construir um outro olhar para esta relação: campo e cidade vistos dentro do princípio da igualdade social e da diversidade cultural. Está incluída neste debate a necessidade de rever a forma arbitrária atual de classificação da população e dos municípios como urbanos ou rurais; ela dá uma falsa visão do significado da população do campo em nosso país, e tem servido como justificativa para a ausência de políticas públicas destinadas a ela.

d) A Educação do Campo participa do debate sobre desenvolvimento, assumindo uma visão de totalidade, em contraposição à visão setorial e excludente que ainda predomina em nosso país; e reforçando a idéia de que é necessário e possível fazer do campo uma opção de vida, vida digna. Nesta perspectiva, é preciso avançar na reflexão que combina diferentes políticas voltadas à população do campo, e que vincula a educação a um projeto de desenvolvimento com diferentes dimensões; isto não pode ser confundido com o atrelamento da educação a modelos econômicos estreitos, visão muito própria da chamada educação rural no Brasil.[9] A Educação do Campo se afirma no combate aos 'pacotes' (tanto agrícolas como educacionais) e à tentativa de fazer das pessoas que vivem no campo instrumentos de implantação de modelos que as ignoram ou escravizam. Também se contrapõe à visão estreita de educação como preparação de mão-deobra e a serviço do mercado.

\section{Luta por políticas públicas que garantam o acesso universal à educação.}

Um dos traços fundamentais que vêm desenhando a identidade do movimento por uma Educação do Campo é a luta do povo do campo por políticas públicas que garantam o seu direito à educação, e a uma educação 
que seja no e do campo. No: o povo tem direito a ser educado no lugar onde vive; Do: o povo tem direito a uma educação pensada desde o seu lugar e com a sua participação, vinculada à sua cultura e às suas necessidades humanas e sociais. (Caldart, 2002)[10]

Somos herdeiros e continuadores da luta histórica pela constituição da educação como um direito universal: um direito humano, de cada pessoa em vista de seu desenvolvimento mais pleno, e um direito social, de cidadania ou de participação mais crítica e ativa de todos na dinâmica da sociedade. Como direito não pode ser tratada como serviço nem como política compensatória; muito menos como mercadoria.

A Educação do Campo tem se desenvolvido em muitos lugares através de programas, de práticas comunitárias, de experiências pontuais. Não se trata de desvalorizar ou de ser contra estas iniciativas porque elas têm sido uma das marcas de nossa resistência. Mas é preciso ter clareza de que isto não basta. A educação somente se universaliza quando se torna um sistema, necessariamente público. Não pode ser apenas soma de projetos e programas. Por isso nossa luta é no campo das políticas públicas, porque esta é a única maneira de universalizar o acesso de todo o povo do campo à educação.

Não se trata, então de ficar em um debate meramente corporativo, e igualmente setorial. A Educação do Campo precisa estar inserida no debate geral sobre a educação nacional, vinculado por sua vez ao debate mais amplo sobre um projeto de desenvolvimento de país. E no debate atual sobre a construção de um sistema nacional de educação, é preciso não deixar de discutir qual é o lugar da Educação do Campo dentro dele, e no próprio processo de sua construção: como pensar em uma política nacional de Educação do Campo sem considerar a necessidade de um sistema nacional de educação?

E é preciso pensar também que tratar do direito universal à educação é mais do que tratar da presença de todas as pessoas na escola; é passar a olhar para o jeito de educar quem é sujeito deste direito, de modo a construir uma qualidade de educação que forme as pessoas como sujeitos de direitos, capazes de fazer a luta permanente pela sua conquista. Neste sentido, a experiência dos Movimentos Sociais na formação da consciência do direito precisa ser recuperada e valorizada pela Educação do Campo.

\section{Projeto de educação dos e não para os camponeses.}

A Educação do Campo se identifica pelos seus sujeitos: é preciso compreender que por trás de uma indicação geográfica e de dados estatísticos isolados, está uma parte do povo brasileiro que vive neste lugar e desde as relações sociais específicas que compõem a vida no e do campo, em suas diferentes identidades e em sua identidade comum; estão pessoas de diferentes idades, estão famílias, comunidades, organizações, movimentos sociais... A perspectiva da Educação do Campo é exatamente a de educar as pessoas que trabalham no campo, para que se encontrem, se organizem e assumam a condição de sujeitos da direção de seu destino.

Trata-se de uma educação dos e não para os sujeitos do campo. Feita sim através de políticas públicas, mas construídas com os próprios sujeitos dos direitos que as exigem. A afirmação deste traço que vem desenhando nossa identidade é especialmente importante se levamos em conta que na história do Brasil, toda vez que houve alguma sinalização de política educacional ou de projeto pedagógico específico isto foi feito para o meio rural e muito poucas vezes com os ou ainda menos pelos sujeitos do campo. Além de não reconhecer o povo do campo como sujeito da política e da pedagogia, sucessivos governos tentaram sujeitá- 
lo a um tipo de educação domesticadora e atrelada a modelos econômicos perversos.

Este é um traço do projeto político e pedagógico da Educação do Campo que não podemos perder jamais, porque estamos diante de uma grande novidade histórica: a possibilidade efetiva de os camponeses assumirem a condição de sujeitos de seu próprio projeto educativo; de aprenderem a pensar seu trabalho, seu lugar, seu país, e sua educação. É a concretização da Pedagogia do Oprimido, talvez entre seus sujeitos mais legítimos...

E precisamos ainda desdobrar na reflexão do projeto da Educação do Campo o debate sobre pedagogias e metodologias que trabalhem a capacitação real do povo para esta atuação como sujeito; sujeito da construção de políticas públicas, sujeito da construção de projetos de desenvolvimento, sujeito de sua organização coletiva e de lutas sociais, sujeito da reflexão política, e da reflexão pedagógica sobre seu próprio processo de formação como sujeito...

\section{Movimentos Sociais como sujeitos da Educação do Campo.}

A Educação do Campo somente se tornará uma realidade efetiva, enquanto ideário, enquanto projeto educativo e enquanto política pública de educação, se permanecer vinculada aos Movimentos Sociais. O protagonismo dos camponeses, ou mais amplamente dos trabalhadores e das trabalhadoras do campo, na construção deste projeto, tem sido garantido através do protagonismo dos Movimentos Sociais na luta e no debate político e pedagógico da Educação do Campo. O do campo não se refere, pois, a uma participação espontânea e desorganizada do povo, facilmente manipulada e neutralizada. Um dos objetivos políticos da Educação do Campo é ajudar na mobilização e organização dos camponeses em Movimentos Sociais que fortaleçam e identifiquem sua presença coletiva na sociedade, e que sejam seu espaço principal de educação para a participação e para as lutas sociais necessárias.

Isto não significa afirmar que a Educação do Campo é um projeto de educação apenas daquelas pessoas que já participam de Movimentos Sociais, ou que neste debate não há lugar para o Estado ou para outras entidades e categorias sociais. A Educação do Campo precisa pensar a educação do conjunto da população do campo, mas seu projeto educativo está sendo construído desde uma perspectiva de classe e desde a experiência política e pedagógica dos Movimentos Sociais Camponeses; isso também é algo inédito na história de nosso país, e é um traço de nossa identidade a ser cultivado com muito cuidado; ao mesmo tempo se constitui como um grande desafio para os Movimentos: descentrar-se de suas demandas educativas específicas para pensar em um projeto de educação para o conjunto do povo brasileiro que trabalha e vive no e do campo.

É este vínculo com as lutas sociais, com os movimentos sociais, que coloca a Educação do Campo como herdeira e ao mesmo tempo construtora da Pedagogia do Movimento, que aos poucos se conforma como componente importante da tradição pedagógica vinculada a processos de transformação social e de emancipação humana.

A Pedagogia do Movimento reflete sobre como os Movimentos Sociais se constituem como matriz pedagógica à medida que atuam como educadores ou como sujeitos pedagógicos da formação de novos sujeitos sociais, capazes de interferir de alguma forma no cenário político da sociedade atual. E os 
Movimentos fazem isso não apenas quando ou se trabalham no campo específico da educação, mas também e principalmente quando sua dinâmica de luta e de organização intencionaliza um projeto de formação. Deste projeto de formação humana que vem sendo desenhado por Movimentos Sociais de nosso tempo, é possível extrair algumas preciosas lições de pedagogia sobre como intencionalizar muitas das práticas de Educação do Campo.

Esta visão pedagógica inverte a lógica de pensar a educação: em vez de pensar uma ação pedagógica para dinamizar ou "modernizar" a sociedade rural, como é a visão da chamada educação rural, o que temos que pensar é em ações pedagógicas sintonizadas com a dinâmica social do campo, acelerada pela presença dos Movimentos Sociais. Isto implica em todo um outro tipo de reflexão pedagógica e metodológica a ser feita em cada um dos espaços intencionais de educação, incluindo a escola.

O vínculo da Educação do Campo com os Movimentos Sociais aponta, além disso, para algumas dimensões da formação humana que não podem ser esquecidas em seu projeto político e pedagógico: pensar que precisamos ajudar a educar não apenas trabalhadores do campo, mas também lutadores sociais, militantes de causas coletivas e cultivadores de utopias sociais libertárias. Que formação dá conta disso, e como desenvolvê-la nos diferentes espaços educativos, são questões que também precisam ser desdobradas na discussão deste projeto.

\section{Vínculo com a matriz pedagógica do trabalho e da cultura.}

A Educação do Campo nasceu colada ao trabalho e à cultura do campo. E não pode perder isso em seu projeto. A leitura dos processos produtivos e dos processos culturais formadores (ou deformadores) dos sujeitos do campo é tarefa fundamental da construção do projeto político e pedagógico da Educação do Campo.

O trabalho forma/produz o ser humano: a Educação do Campo precisa recuperar toda uma tradição pedagógica de valorização do trabalho como princípio educativo, de compreensão do vínculo entre educação e produção, e de discussão sobre as diferentes dimensões e métodos de formação do trabalhador, de educação profissional, cotejando todo este acúmulo de teorias e de práticas com a experiência específica de trabalho e de educação dos camponeses.

O projeto da Educação do Campo precisa estar atento para os processos produtivos que conformam hoje 0 ser trabalhador do campo, e participar do debate sobre as alternativas de trabalho e opções de projetos de desenvolvimento locais e regionais que podem devolver dignidade para as famílias e as comunidades camponesas. Pensar isso do ponto de vista pedagógico mais amplo, enquanto processos de humanizaçãodesumanização dos sujeitos, e pensar como estes processos podem/devem ser trabalhados nos diferentes espaços educativos do campo. O que significa hoje fazer a formação das trabalhadoras e dos trabalhadores jovens e adultos do campo? E o que significa educar as crianças e os adolescentes das escolas do campo, levando em conta a formação de sua identidade de trabalhador, e especificamente sua identidade de trabalhador do campo?

A cultura também forma o ser humano e dá as referências para o modo de educá-lo; são os processos culturais que ao mesmo tempo expressam e garantem a própria ação educativa do trabalho, das relações 
sociais, das lutas sociais: a Educação do Campo precisa recuperar a tradição pedagógica que nos ajuda a pensar a cultura como matriz formadora, e que nos ensina que a educação é uma dimensão da cultura, que a cultura é uma dimensão do processo histórico, e que processos pedagógicos são constituídos desde uma cultura e participam de sua reprodução e transformação simultaneamente.

Quando dizemos que os Movimentos Sociais são educativos é exatamente compreendendo que estão provocando processos sociais que ao mesmo tempo reproduzem e transformam a cultura camponesa, ajudando a conformar um novo jeito de ser humano, um novo modo de vida no campo, uma nova compreensão da história. A Educação do Campo precisa ser a expressão (e o movimento) da cultura camponesa transformada pelas lutas sociais do nosso tempo.

Pensar a educação vinculada à cultura significa construir uma visão de educação em uma perspectiva de longa duração, ou seja, pensando em termos de formação das gerações. E isto tem a ver especialmente com a educação de valores. A Educação do Campo, além de se preocupar com o cultivo da identidade cultural camponesa, precisa recuperar os veios da educação dos grandes valores humanos e sociais: emancipação, justiça, igualdade, liberdade, respeito à diversidade, bem como reconstruir nas novas gerações o valor da utopia e do engajamento pessoal a causas coletivas, humanas.

O vínculo com as matrizes formadoras do trabalho e da cultura nos remete a pensar em outro traço muito importante para a Educação do Campo: sua dimensão de projeto coletivo e de concepção mais ampliada do que sejam as relações pedagógicas. $O$ trabalho e a cultura são produções e expressões necessariamente coletivas e não individuais. Raiz cultural, que inclui o vínculo com determinados tipos de processos produtivos, significa pertença a um grupo, identificação coletiva. As relações interpessoais (educadoreducando) são inerentes à concretização do ato educativo, mas se trata de pensá-las não como relação indivíduo-indivíduo para formar indivíduos, mas sim como relações entre pessoas culturalmente enraizadas, para formar pessoas que se constituem como sujeitos humanos e sociais.

Esta compreensão pode fazer muita diferença no jeito de fazer a educação e por isso deve ser uma preocupação específica na formação dos educadores e das educadoras do campo.

\section{Valorização e formação dos educadores.}

A Educação do Campo também se identifica pela valorização da tarefa específica das educadoras e dos educadores. Sabemos que em muitos lugares elas e eles têm sido sujeitos importantes da resistência social da população do campo, especialmente nas escolas. E que têm estado à frente de muitas lutas pelo direito à educação, e para impedir o fechamento de escolas nas comunidades camponesas.

A Educação do Campo têm construído um conceito mais alargado de educador. Para nós é educadora aquela pessoa cujo trabalho principal é o de fazer e o de pensar a formação humana, seja ela na escola, na família, na comunidade, no movimento social...; seja educando as crianças, os jovens, os adultos ou os idosos. Nesta perspectiva todos somos de alguma forma educadores, mas isto não tira a especificidade desta tarefa: nem todos temos como trabalho principal o de educar as pessoas e o de conhecer a complexidade dos processos de aprendizagem e de desenvolvimento do ser humano, em suas diferentes gerações.

file://C:|Documents and Settings\AdministradorlMeus documentos\Minhas Webs\NED... 28/8/2008 
Construir a Educação do Campo significa formar educadores e educadoras do campo para atuação em diferentes espaços educativos. E se defendemos uma formação específica é porque entendemos que boa parte deste ideário que estamos construindo é algo novo em nossa própria cultura. Há uma nova identidade de educador que precisa ser cultivada, ao mesmo tempo em que há toda uma tradição pedagógica e um acúmulo de conhecimentos sobre a arte de educar que precisa ser recuperada e trabalhada desde esta intencionalidade educativa da Educação do Campo.

Por isso o projeto político e pedagógico da Educação do Campo deve incluir uma reflexão sobre qual o perfil do profissional de educação de que precisamos, e sobre como se faz esta formação. Pensar sobre como os educadores e as educadoras têm se formado nos próprios processos de construção da Educação do Campo, e como isso pode ser potencializado pedagogicamente em programas e políticas de formação específicas.

\section{Escola como um dos objetos principais da Educação do Campo.}

A Educação do Campo não cabe em uma escola, mas a luta pela escola tem sido um de seus traços principais: porque a negação do direito à escola é um exemplo emblemático do tipo de projeto de educação que se tenta impor aos sujeitos do campo; porque o tipo de escola que está ou nem está mais no campo tem sido um dos componentes do processo de dominação e de degradação das condições de vida dos camponeses; porque a escola tem uma tarefa educativa fundamental, especialmente na formação das novas gerações; e porque a escola pode ser um espaço efetivo de fazer acontecer a Educação do Campo, e pode ter um papel importante na disputa de hegemonia de projeto de campo, de sociedade e de formação humana.

Nessa perspectiva, a escola terá tanto mais lugar no projeto político e pedagógico da Educação do Campo se não se fechar nela mesma, vinculando-se com outros espaços educativos, com outras políticas de desenvolvimento do campo, e com a própria dinâmica social em que estão envolvidos os seus sujeitos.

Compreender o lugar da escola na Educação do Campo é compreender que ser humano ela precisa ajudar a formar, e como pode contribuir com a formação dos novos sujeitos sociais que vêm se constituindo no campo hoje. A escola precisa cumprir a sua vocação universal de ajudar no processo de humanização das pessoas, e com as tarefas específicas que pode assumir nesta perspectiva. Ao mesmo tempo é chamada a estar atenta à particularidade dos processos sociais do seu tempo histórico e ajudar na formação das novas gerações de trabalhadores e de militantes sociais.

\section{A ESCOLA NO PROJETO DA EDUCAÇÃO DO CAMPO}

Não se trata de propor algum modelo pedagógico para as escolas do campo, mas sim de construir coletivamente algumas referências para processos pedagógicos a serem desenvolvidos pela escola, e que permitam que ela seja obra e identidade dos sujeitos que ajuda a formar, com traços que a identifiquem com o projeto político e pedagógico da Educação do Campo.

Para construir referências comuns às escolas vinculadas a este projeto de educação precisamos antes pensar em alguns aspectos principais do que é o trabalho específico da escola, ou quais as funções sociais que assume ou deve assumir, já dialogando com a intencionalidade política e pedagógica da Educação do Campo. Estamos pensando ainda em aspectos ou tarefas gerais, que depois precisam ser desdobradas e 
pensadas pedagogicamente a partir dos diferentes sujeitos que estão nas escolas concretas, do vínculo que cada escola pode ter com projetos de desenvolvimento local ou regional, e levando em conta as diferenças de cada ciclo da vida e de cada modalidade de escola.

Alguns aspectos do trabalho específico da escola que em nosso entender merecem destaque e sobre os quais deveremos aprofundar nossa reflexão:

\section{Socialização ou vivência de relações sociais.}

Esta é uma tarefa historicamente atribuída à escola: a socialização das novas gerações. Só que esta socialização geralmente foi vista como adaptação das pessoas ao formato da sociedade existente; educar para diminuir ao máximo o número dos chamados "desajustados" e que insistem em querer mudar o mundo.

Mas podemos pensar a socialização desde um outro ponto de vista e então perceber que de fato esta é uma tarefa importante e específica (embora não exclusiva) da escola: compreendê-la como tempo e espaço de vivência de relações sociais que vão formando um determinado jeito de ser humano, que bem pode ser o que se constitui como sujeito consciente de transformações, inclusive da sociedade. Ou seja, a socialização pode se dar desde a referência do individualismo ou da cooperação e da preocupação com o bem-estar coletivo; dos objetivos de consumo e de 'se dar bem na vida', ou dos valores da justiça e da igualdade; desde a perspectiva de mudar a realidade ou de deixar tudo como está, acomodando-se à lógica social dominante.

A escola costuma ser um dos primeiros lugares em que a criança experimenta, de modo sistemático, relações sociais mais amplas das que vive em família, e de uma intencionalidade política e pedagógica nessa dimensão pode depender muitos dos traços de seu caráter, muitos dos valores que assuma em sua vida. Mesmo as crianças que têm cedo uma experiência social muito densa que é a de participar com suas famílias de Movimentos Sociais, como é o caso das crianças Sem Terra, por exemplo, é na escola que costumam encontrar o espaço para trabalhar reflexiva e emocionalmente as relações sociais vividas na luta pela terra, e então incorporá-las como traços culturais em sua vida infantil, e talvez também depois.

Na escola sempre há algum tipo de socialização, porque sempre há relações sociais. Mas nem sempre isto integra o projeto pedagógico e a intencionalidade do trabalho dos educadores. E neste aspecto, é preciso ter bem presente que o principal componente curricular da escola é ela mesma: a experiência cultural de escola é pedagogicamente muito mais significativa do que a tematização da socialização ou apenas a tentativa de transformar determinadas relações sociais em conteúdo discursivo de sala de aula.

A escola socializa a partir das práticas que desenvolve; através do tipo de organização do trabalho pedagógico que seus sujeitos vivenciam; através das formas de participação que constituem seu cotidiano. São as ações que revelam as referências culturais das pessoas, educandos e educadores. E é trazendo à tona estas referências que elas podem ser coletivamente recriadas e reproduzidas.

A Educação do Campo precisa incluir em seu projeto pedagógico uma reflexão cuidadosa e mais aprofundada sobre como acontecem no cotidiano da escola os processos de socialização, sua relação com os processos de conservação e de criação de culturas, e com a formação dos novos sujeitos sociais do campo. Também precisa fazer a reflexão específica sobre que outros processos de socialização estão formando hoje as novas gerações de trabalhadores e trabalhadoras do campo, e que traços devem ser 
enfatizados pela intencionalidade pedagógica da escola na perspectiva de um novo projeto de desenvolvimento.

\section{Construção de uma visão de mundo.}

A escola muitas vezes trabalha conteúdos fragmentados, idéias soltas, sem relação entre si e muito menos com a vida concreta; são muitos estudos e atividades sem sentido, fora de uma totalidade mais ampla, que deveria ser exatamente a de um projeto de formação humana.

É tarefa específica da escola ajudar a construir um ideário que orienta a vida das pessoas, e inclui também as ferramentas culturais de uma leitura mais precisa da realidade em que vivem. E ajudar a construir uma visão de mundo significa em primeiro lugar fazer o inventário das concepções que educandos e educadores carregam em si; significa também enraizar as pessoas na história, para que se compreendam como parte de um processo histórico. E isso tudo para tornar consciente, explicitar, interpretar, questionar, organizar, firmar ou revisar idéias e convicções sobre o mundo, sobre a história, sobre a realidade mais próxima, sobre si mesmos.

Para que a escola cumpra esta tarefa é necessário que a escolha dos conteúdos de estudo e a seleção de aprendizados a serem trabalhados em cada momento não seja aleatória, mas feita dentro de uma estratégia mais ampla de formação humana. E que se busque coerência entre teoria e prática; entre o que se estuda e o ambiente cultural da escola. Um bom critério então para a escolha dos conteúdos pode ser este: analisar em que medida se relacionam ou se constituem como ferramentas para a construção de uma visão de mundo, um ideário de vida. Também se eles permitem aos educandos aprender como pensar sobre o que faz, sobre o que estuda, sobre o que pensa.

Na Educação do Campo é preciso refletir sobre como se ajuda a construir desde a infância uma visão de mundo crítica e histórica; como se aprende e como se ensina nas diferentes fases da vida a olhar para a realidade enxergando seu movimento, sua historicidade, e as relações que existem entre uma coisa e outra; como se aprende e como se ensina a tomar posição diante das questões do seu tempo; a respeitar e ao mesmo tempo reconstruir modos de vida; como se aprendem e como se ensinam utopias sociais e como se educam valores humanistas; também como se educa o pensar por conta própria e o dizer a sua palavra, e como se respeita uma organização coletiva.

\section{Cultivo de identidades.}

Esta também é uma das funções da escola: trabalhar com os processos de percepção e de formação de identidades, no duplo sentido de ajudar a construir a visão que a pessoa tem de si mesma (autoconsciência de quem é e com o que ou com quem se identifica), e de trabalhar os vínculos das pessoas com identidades coletivas, sociais: identidade de camponês, de trabalhador, de membro de uma comunidade, de participante de um movimento social, identidade de gênero, de cultura, de povo, de Nação...

E este é, de fato, um aprendizado humano essencial: olhar no espelho do que somos e queremos ser; assumir identidades pessoais e sociais, ter orgulho delas, ao mesmo tempo em que se desafiar no movimento de sua permanente construção e reconstrução. Educar é ajudar a construir e a fortalecer identidades; desenhar rostos, formar sujeitos. E isso tem a ver com valores, modo de vida, memória, cultura. 
As identidades se formam nos processos sociais. O papel da escola será tanto mais significativo se ela estiver em sintonia com os processos sociais vivenciados pelos seus educandos e educadores, e se ela mesma consegue se constituir como um processo social, cumprindo a tarefa da socialização de que tratamos antes, capaz de ajudar a construir e fortalecer identidades.

Pensando desde a intencionalidade política e pedagógica da Educação do Campo, há pelo menos três aspectos que a escola deveria trabalhar com mais ênfase para ajudar no cultivo de identidades:

a) Auto-estima: a escola tem um papel que não pode ser subestimado na formação da auto-estima de seus educandos (e também de seus educadores). E isto é muito importante para a Educação do Campo, já que em muitas comunidades camponesas existe um traço cultural de baixa auto-estima acentuado, fruto de processos de dominação e alienação cultural muito fortes, e que precisa ser superado em uma formação emancipatória dos sujeitos do campo.

Para que a escola assuma a tarefa de fortalecer a auto-estima dos seus educandos, além de todo um trabalho ligado à memória, à cultura, aos valores do grupo, é preciso pensar especialmente na postura dos educadores, e também na transformação das didáticas, ou do jeito de conduzir as atividades escolares. Porque isso vai fazer diferença no sentimento que se forma no educando ao realizá-las. Estudos indicam que o processo de formação da auto-estima de uma pessoa está ligado, por exemplo, ao sentimento de ser capaz de iniciar e realizar atividades por conta própria, e à capacidade de auto-avaliação sobre o que consegue fazer bem, a partir de critérios que lhe são fornecidos pelo ambiente externo. (Bruner, 2001) Isso tem a ver com a própria prioridade didática ao fazer, ou à produção de obras na escola, e também com o jeito de trabalhar estes processos com os educandos.

Este é, sem dúvida, um dos aspectos específicos e pouco estudados do processo de aprendizagem e ensino, e que merece uma boa atenção no pensar a escola desde a perspectiva da Educação do Campo.

b) Memória e resistência cultural: a escola precisa ajudar a enraizar as pessoas em sua cultura: que pode ser transformada, recriada a partir da interação com outras culturas, mas que precisa ser conservada; porque nem é possível fazer formação humana sem trabalhar com raízes e vínculos; porque sem identificar raízes não há como ter projetos. Isto quer dizer que a escola precisa trabalhar com a memória do grupo e com suas raízes culturais; e isto quer dizer também que se deve ter uma intencionalidade específica na resistência à imposição de padrões culturais alienígenas, no combate à dominação cultural e na reconstrução crítica de suas próprias tradições culturais.

Estamos falando, afinal, de como a escola pode ajudar os educandos e as educandas a perder a vergonha de 'ser da roça'; a aprender a 'ser camponês', e a 'ser de Movimento Social'; a aprender a valorizar a história dos seus antepassados, tendo uma visão crítica sobre ela; e a aprender do passado para saber projetar o futuro.

E um bom jeito de trabalhar isso na escola é, por exemplo, contando histórias e estórias que tenham a memória do grupo como referência, assim como trabalhar com diferentes linguagens artísticas que expressem a cultura camponesa e a coloquem em diálogo com outras culturas.

Também aqui é necessário um aprofundamento da Educação do Campo sobre como acontecem os processos culturais e a formação da memória coletiva de um grupo e de sua consciência histórica, e sobre como isso deve ser trabalhado pedagogicamente nas diferentes faixas etárias, e na especificidade das atividades escolares.

c) Militância social: a escola deve ajudar no aprendizado da construção de utopias sociais, porque são elas que permitem relacionar a identidade pessoal com as grandes questões da humanidade; da mesma forma deve se preocupar com a formação da disponibilidade pessoal à militância capaz de transformar estas utopias em projetos que mobilizem grandes massas, e em obras que já iniciem sua concretização.

Estamos falando, pois, de militância no sentido amplo, de engajamento em torno de grandes causas, ações pelo bem de outras pessoas, envolvimento em processos de transformação social, que também podem desembocar na militância política ou na participação direta em organizações, movimentos sociais, partidos políticos. Certamente a escola não consegue realizar por si mesma e isoladamente um tipo de aprendizado 
como este, mas se ela entrar neste movimento pedagógico e ajudar a construir este tipo de convicção e de sentimento, desde a infância, certamente estará prestando um grande serviço à humanidade, tão carente hoje de pessoas dispostas à solidariedade e à militância.

A Educação do Campo precisa aprofundar a reflexão sobre como a escola pode ajudar a cultivar utopias e a formar militantes, respeitando a cultura camponesa e a própria fase da vida em que se encontram os diferentes educandos. É preciso refletir permanentemente sobre a intencionalidade educativa da escola nesta perspectiva, e olhar para os detalhes do seu ambiente educativo tendo presente que grande parte das pedagogias e das didáticas que conhecemos se movimentam no sentido inverso, que é o do individualismo e da alienação social, ainda que seus discursos às vezes se manifestem pela transformação e pelo humanismo.

\section{Socialização e produção de diferentes saberes.}

Na realização do seu trabalho pedagógico, e particularmente na concretização dos aspectos destacados nos pontos anteriores, a escola põe em movimento diferentes saberes e esta é também uma de suas tarefas específicas: socializar e produzir diferentes tipos de saberes e fornecer as ferramentas culturais necessárias ao seu cultivo.

Trata-se de saberes ligados ao mundo da cultura, incluindo os da arte e da estética, saberes ligados ao mundo do trabalho, saberes ligados à dimensão da militância e da luta social, e também os saberes ligados ao mundo do conhecimento, ou específicos dos processos de aprendizagem escolar: aprender a ler, a escrever, a gostar de ler e de escrever, a construir conceitos, a ler cientificamente a realidade, a fazer pesquisa, a tomar posição diante de diferentes idéias...

Trabalhar com diferentes saberes significa em primeiro lugar não hierarquizá-los, nem considerar que eles são propriedade somente dos educadores, ou dos educandos. Todos somos detentores de saberes, e é preciso que o diálogo entre educadores e educandos permita a cada um ter consciência dos seus saberes, além de ampliá-los e diversificá-los através da partilha e da produção coletiva de novos saberes.

Também significa compreender que há saberes de diferentes tipos e naturezas, e que também são diferentes os processos de sua apropriação e produção. Há saberes que se constituem em idéias, outros em posturas e comportamentos, outros em habilidades, o que implica em metodologias e didáticas igualmente

diferenciadas. $\mathrm{E}$ há saberes, como os ligados ao mundo do trabalho e da cultura que têm sua origem fora, e às vezes bem longe da escola, e a ela cabe uma aproximação crítica, nem tanto para tentar trazer estes saberes para o seu interior, o que nem sempre é possível sem trair sua natureza, mas para provocar a inserção dos educandos em processos sociais capazes de produzi-los. Ao mesmo tempo cabe à escola ajudar na reflexão coletiva sobre estes saberes, relacionando-os entre si e potencializando-os nos processos de socialização dos educandos, de construção de sua visão de mundo e de suas identidades, enfim em seu processo mais amplo de humanização ou de formação humana.

A Educação do Campo deve incluir em seu debate político e pedagógico a questão de que saberes são mais necessários aos sujeitos do campo, e podem contribuir na preservação e na transformação de processos culturais, de relações de trabalho, de relações de gênero, de relações entre gerações no campo; também 
que saberes podem ajudar a construir novas relações entre campo e cidade. Além disso, é preciso discutir sobre como e onde estão sendo produzidos hoje estes diferentes saberes, qual a tarefa da escola em relação a cada um deles, e também que saberes especificamente escolares podem ajudar na sua produção e apropriação cultural...

\section{Esta é uma reflexão que deve continuar}

A Educação do Campo precisa aprofundar sua reflexão sobre que formato de escola é capaz de dar conta destas tarefas indicadas, sem subestimar nem superestimar o papel da escola nos processos de formação humana. Além disso, precisamos nos dedicar ao estudo de didáticas e metodologias que consigam traduzir esta concepção de escola e este projeto político e pedagógico em cotidiano escolar.

Há reflexões recentes sobre como acontecem os processos de aprendizagem e ensino, e como se constroem os saberes especificamente escolares que, cotejadas com as práticas que nós já construímos, podem nos ajudar a passar de intenções a alternativas concretas de um trabalho pedagógico que ajuíze estas concepções, e que participe de fato na construção desse novo projeto de campo e de educação.

\section{Referências Bibliográficas}

1. ARROYO, Miguel e FERNANDES, Bernardo Mançano. Por uma educação básica do campo: a educação básica e o movimento social no campo. V.2. Brasília, 1999.

2. BENJAMIN, César e CALDART, Roseli Salete. Por uma educação básica do campo: projeto popular e escolas do campo. V.3. Brasília, 1999.

3. BRUNER, Jerome. A cultura da educação. Porto Alegre: Artmed Editora, 2001.

4. CALAZANS, Maria Julieta Costa. Para compreender a educação do Estado no meio rural - traços de uma trajetória. In.: THERRIEN, Jacques e DAMASCENO, Maria Nobre (coords). Educação e Escola no Campo. Campinas: Papirus, 1993, p. 15-40.

5. CALDART, Roseli Salete. Por Uma Educação do Campo: traços de uma identidade em construção. In.: Por Uma Educação do Campo: Identidade e Políticas Públicas. V. 4. Brasília, 2002, p. 25-36.

6. CARVALHO, Horacio Martins de. A questão agrária e o fundamentalismo neoliberal no Brasil. Texto, 2004.

7. FERNANDES, Bernardo Mançano. Delimitação conceitual de campesinato. Texto, 2004.

8. KOLLING, Edgar, NERY, Israel e MOLINA, Mônica Castagna (Orgs). ). Por uma educação básica do campo. V.1. Brasília, 1999.

9. KOLLING, Edgar Jorge, CERIOLI, Paulo Ricardo e CALDART, Roseli Salete (orgs). Por Uma Educação do Campo: Identidade e Políticas Públicas. V. 4. Brasília, 2002.

10. OLIVEIRA, Ariovaldo Umbelino. Barbárie e Modernidade: as transformações no campo e o agronegócio no Brasil. Texto, 2004.

[1] Texto produzido a partir da exposição "A construção da identidade da Educação do Campo", desenvolvida no Seminário Estadual da Educação do Campo promovido pela Secretaria de Estado da Educação do Paraná de 9 a 11 de março de 2004.

[2] Do Setor de Educação do Movimento dos Trabalhadores Rurais Sem Terra e da Articulação Nacional Por Uma Educação do Campo. Doutora em Educação pela Universidade Federal do Rio Grande do Sul.

[3] Para conhecer o debate preparatório e posterior a esta Conferência Nacional e que deu origem à articulação nacional Por Uma Educação do Campo é importante consultar a Coleção Por Uma Educação do Campo editada a partir de 1999. Participaram da promoção da I Conferência Nacional em Luziânia, GO, o MST, a CNBB, a UnB, a UNESCO e o UNICEF. 
[4] Desde 2003 existe no MEC um Grupo Permanente de Trabalho de Educação do Campo, que inclui a participação de representantes de Movimentos Sociais e Sindicais de trabalhadores e trabalhadoras do campo, e em 2004 deve entrar em funcionamento uma Coordenadoria da Educação do Campo vinculada à Secretaria de Educação Continuada, Alfabetização e Diversidade (SECAD/MEC).

[5] Sobre o Seminário de 2002 ver Coleção Por Uma Educação do Campo no 04, "Educação do Campo: identidade e políticas públicas", dezembro de 2002.

[6] Camponeses entendidos aqui no sentido de diferentes grupos de trabalhadores e trabalhadoras do campo cujo processo de reprodução social se faz na contraposição às relações capitalistas de produção, ainda que subordinado a elas. Elementos do debate atual sobre o campesinato podem ser encontrados em Fernandes, 2004.

[7] Hoje há também o surgimento em alguns lugares da expressão "educação no campo", que se vincula a grupos com estes mesmos interesses políticos conservadores.

[8] Uma análise detalhada do que representa para a população trabalhadora do campo este modelo de agricultura pode ser encontrada em Oliveira, A. U., 2004 e Carvalho, H. M., 2004.

[9] Uma análise da relação entre educação rural e modelo de agricultura capitalista no Brasil pode ser encontrada no texto de Julieta Costa Calazans: Para compreender a educação do Estado no meio rural. (Therrien e Damasceno, 1993).

[10] $\mathrm{Na}$ identificação dos traços do projeto político e pedagógico da Educação do Campo recupero aqui elementos de uma reflexão iniciada no texto Por uma Educação do Campo: traços de uma identidade em construção, 2002. 